\title{
Information about a Report by A.I. Morozov at the Seminar on Theoretical Problems of Soil Science
}

\author{
O. V. Chernova \\ Several Institute of Ecology and Evolution, Russian Academy of Sciences, Leninskii pr. 33, Moscow, 117071 Russia
}

DOI: $10.1134 / \mathrm{S} 1064229309040164$

On October 15, 2008, a regular session of the seminar on theoretical problems of soil science headed by Academician G.V. Dobrovol'skii took place at the Faculty of Soil Science of Moscow State University. At this session, a leading researcher of the Russian Research Center Kurchatov Institute, Doctor of Physicomathematical Sciences A.I. Morozov, presented his book O pochve i pochvovedenii. Vzglyad so storony (On Soil and Soil Science: A Look from the Outside). In his report, Morozov explained the reasons for his keen interest in the problems of soil science and shared his views on the organization and functioning of soil as a natural body; he also expressed his opinion about the major results and further prospects of theoretical pedology as a fundamental science. The ideas and arguments of Morozov are clearly outlined in his book and in a number of papers devoted to different problems of soil science.

The report provoked a discussion with active participation of well-known soil scientists and specialists in neighboring fields of science.

The soil scientists A.N. Gennadiev (Dr. Geogr.), I.I. Sudnitsyn (Dr. Biol.), A.S. Vladychenskii (Dr. biol.), V.O. Targulian (Dr. Biol.), and some others disagreed with most of the theoretical innovations suggested by Morozov. In particular, they argued that the role of the biotic factor in soil formation is unfairly exaggerated by him, whereas the role of other factors is depreciated. At the same time, several participants (e.g., E.V. Shein (Dr. Biol.)) stressed that the works on modeling soil processes prepared by Morozov in cooperation with soil scientists are marked by their high scientific quality.

Specialists in microbiology, doctors of biological sciences P.M. Kozhevin, A. Kurakov, and V.A. Terekhova, pointed to the inadequately great role of mycorrhizal fungi in the theory of soil formation developed by Morozov. They argued that the great biomass and population density of mycorrhizal fungi in some ecosystems should not be interpreted in terms of the dominant functional role of these organisms.

Academician G.V. Dobrovol'skii thanked A.I. Morozov for his report and emphasized the importance of joint discussions of the problems of pedology together with specialists in other fields of science. At the same time, he disagreed with the opinion of Morozov about the current state of pedology as a scientific discipline and with the new definition of soil given by Morozov. From the viewpoint of Dobrovol'skii, this definition is extremely one-sided and does not reflect the essence of soils as specific natural bodies.

In conclusion of the seminar, the participants acknowledged the usefulness of the discussion of soil science problems with specialists in neighboring sciences and stressed the importance of some ideas of Morozov about further development of pedology. 